\title{
TRICOMONOSE E CAMPILOBACTERIOSE EM BOVINOS: REVISÃO DE LITERATURA
}

\author{
Mônica Zuchelli Jaguszeski ${ }^{1}$ \\ Geovan Vendruscolo ${ }^{1}$ \\ Adalgiza Pinto-Neto ${ }^{2}$ \\ Marcelo Falci Mota ${ }^{2}$ \\ Antônio Campanha Martinez ${ }^{3}$ \\ Luiz Sérgio Merlini ${ }^{4}$ \\ Rodolfo Berber ${ }^{5}$
}

\begin{abstract}
JAGUSZESKI, M. Z.; VENDRUSCOLO, G.; PINTO-NETO, A.; MOTA, M. F.; MARTINEZ, A. C.; MERLINI, L. S.; BERBER. R. Tricomonose e Campilobacteriose em bovinos: revisão de literatura. Arq. Ciênc. Vet. Zool. UNIPAR, Umuarama, v. 20, n. 1, p. 41-44-, jan./mar. 2017.
\end{abstract}

RESUMO: O aumento da produção de leite no Brasil tem sido essencial para o crescimento do país no mercado internacional, com destaque para a região Sul do país. Com o avanço tecnológico na atividade leiteira, avançou também o cuidado com a sanidade dos rebanhos, que engloba o manejo sanitário da reprodução desses rebanhos. A Tricomonose e a Campilobacteriose são doenças sexualmente transmissíveis que afetam bovinos em várias idades. Tritrichomonas foetus é o agente causador da Tricomonose e C. fetus subsp. venerealis o da Campilobacteriose, sendo, respectivamente, um protozoário e uma bactéria Gram-negativa. O diagnóstico dessas doenças se dá via coleta de lavado prepucial ou cervicovaginal, para a pesquisa de Tritrichomonas spp, e pelo swab prepucial ou cervicovaginal para a pesquisa de Campylobacter spp. Não há tratamento específico para essas doenças, visto que o controle e profilaxia baseiam-se na retirada dos machos portadores do rebanho, ou realização de descanso reprodutivo de quatro ou cinco estros nas fêmeas, já que as mesmas eliminam os agentes etiológicos. Diante do exposto é necessário reconhecer a necessidade de estudos relacionados a Tricomonose e Campilobacteriose em rebanhos leiteiros, principalmente aqueles inseridos em sistema de produção familiar, subsidiando essa revisão de literatura. PALAVRAS-CHAVE: Bovinos de leite. Doenças reprodutivas. Manejo sanitário.

\section{TRICHOMONIASIS AND CAMPYLOBACTERIOSIS IN CATTLE: A LITERATURE REVIEW}

\begin{abstract}
The increase in dairy production in Brazil has been essential to the country's growth in the international market, especially in the southern region of the country. With the technological advances in dairy farming, the caring for the health of herds has also increased, as well as the health management of the reproduction of these animals. Trichomoniasis and campylobacteriosis are sexually transmitted diseases that affect cattle at different ages. Tritrichomonas fetus is a protozoan that promotes Trichomoniasis and C. fetus subsp. venerealis is a gram-negative bacterium that promotes campylobacteriosis. In order to diagnose these diseases, the prepucial or cervicovaginal wash has been collected for Tritrichomonas spp. and the preputial or cervicovaginal swab has been collected for Campylobacter spp. There is no specific treatment for these diseases, since the control and prophylaxis are based on the removal of infected males, or in carrying out reproductive rest between four or five estrous cycles in females, since these actions can eliminate the etiologic agent. Thus, it is important to study trichomoniasis and campylobacteriosis in dairy herds, especially those placed in family farming, supporting this literature review.
\end{abstract}

KEYWORDS: Dairy cattle. Health management. Reproductive diseases.

\section{TRICOMONIASIS Y CAMPILOBACTERIOSIS EN GANADO: REVISIÓN DE LITERATURA}

RESUMEN: El aumento de la producción de leche en Brasil ha sido esencial para el crecimiento del país en el mercado internacional, especialmente en la región sur del país. Con los avances tecnológicos en la industria lechera también se avanzó el cuidado con la salud de los rebaños, que incluye el manejo sanitario de la reproducción de esos rebaños. La tricomoniasis y la campilobacteriosis son enfermedades sexualmente transmisibles que afectan al ganado de diferentes edades. Tritrichomonas fetus es el agente causante de la tricomoniasis y C. fetus subsp. venerealis o de la campilobacteriosis, siendo, respectivamente, un protozoos y una bacteria Gram- negativa. El diagnóstico de esas enfermedades se produce a través de colección de lavado de prepucio o cervicovaginal, para la investigación de Tritrichomonas spp, y por el swab prepucio o cervicovaginal para la investigación de Campylobacter spp. No existe tratamiento específico para esas enfermedades, ya que el control y profilaxis se basan en la retirada de los machos portadores del rebaño, o realización de descanso reproductivo de cuatro o

DOI: https://doi.org/10.25110/arqvet.v20i1.2017.6319

${ }^{1}$ Acadêmicos do Curso de Medicina Veterinária - Campus Realeza-UFFS.

${ }^{2}$ Docentes do Curso de Medicina Veterinária. Campus Realeza-UFFS. Correspondência aos autores: adalgiza.neto@uffs.edu.br; adalgiza.uffs@gmail.com

${ }^{3}$ Docente. Programa de Pós-Graduação em Saúde e Produção Animal Sustentável. Universidade Estadual de Maringá. Campus Umuarama.

${ }^{4}$ Docente. Programa de Pós-Graduação em CiênciaAnimal. Universidade Paranaense. Campus Umuarama.

${ }^{5}$ Docente do Curso de Medicina Veterinária. Campus Sinop. Universidade Federal do Mato Grosso. 
cinco celos en las hembras, pues las mismas eliminan los agentes etiológicos. Delante el expuesto, es necesario reconocer la necesidad de realizar estudios relacionados con la tricomoniasis y campilobacteriosis en rebaños lecheros, especialmente los situados en el sistema de producción familiar, subsidiando esa revisión de literatura.

PALABRAS CLAVE: Ganado lechero. Enfermedades reproductivas. Manejo sanitario.

\section{Introdução}

O Brasil vem apresentando aumento gradativo na produção leiteira, batendo o recorde no ano de 2008 na exportação de produtos lácteos, em que os incrementos registrados ultrapassaram 5\% ao ano (SEAB/DERAL, 2013). Dados do Instituto Brasileiro de Geografia e Estatística (IBGE) indicaram que no ano de 2011 o país produziu 32 bilhões de litros, 4,4 \% superior à produção de 2010 (30,7 bilhões de litros). O cenário da atividade leiteira brasileira mostra que as Regiões Sudeste e o Sul se destacam nesta atividade, com participação de 61,8\%, dos 32 bilhões produzidos em 2011.

O Estado do Paraná é o terceiro maior estado produtor de leite no Brasil, ficando atrás de Minas Gerais e Rio Grande do Sul, primeiro e segundo colocados respectivamente, sendo que a produção paranaense representa $10,6 \%$ da produção total do Brasil (SEAB/DERAL, 2013).

O Sudoeste Paranaense é uma região onde a agricultura tem grande importância, se destacando atualmente pelo crescimento da produção leiteira que tem transformado a Região em uma importante área de captação e industrialização do leite (CAMILO, 2012), o que representa 5,37\% da produção do Paraná (SEAB/DERAL, 2013).

Há vários fatores importantes na pecuária leiteira, associados à rentabilidade da atividade, destaca-se a reprodução que afeta a produtividade dependente de fatores nutricionais, genéticos, sanitários e, acima de tudo, o manejo adequado (LEAL et al., 2012).

Diante disso, o pequeno produtor busca cada vez melhorar a qualidade do leite e da ordenha, considerando os aspectos químicos, físicos e microbiológicos, e a genética dos animais. No entanto, a sanidade reprodutiva do rebanho ainda é insuficiente, por fatores desde a falta de informações do produtor, a dificuldade de diagnóstico das doenças reprodutivas, comprometendo assim a eficiência reprodutiva do rebanho.

A eficiência reprodutiva (ER) de um rebanho é um dos componentes mais importantes no desempenho econômico de uma propriedade de produção de leite (LEITE et al, 2001), sendo que doenças infecciosas, como a Tricomomonose e a Campilobacteriose influenciam negativamente a ER de rebanhos bovinos.

Segundo Nascimento e Santos (2011), a Campilobacteriose bovina é uma doença bacteriana que acomete o trato reprodutivo, causando infertilidade temporária e abortos ocasionais. A Tricomonose ou Tricomoníase, causada por protozoário, também acomete o trato reprodutivo, levando à morte embrionária, infertilidade temporária, aborto até o quinto mês de gestação, além de maceração fetal e piometra. Ambas as enfermidades são transmitidas venereamente pelo touro contaminado.

O PCR, tanto convencional quanto a multiplex, se mostraram bastante eficazes e úteis para o diagnóstico de Tricomonose e Campilobacteriose (BOTELHO, 2014).

As doenças que afetam a reprodução de bovinos contribuem em grande parte para que os índices zootécnicos e se mantenham baixo. Porém, doenças que apresentam manifestações evidentes têm empregado maior interesse, assim há a implantação dos programas de controle e/ou erradicação (LEAL et al., 2012).

Considerando a importância da cadeia do leite na Região Sudoeste do Paraná que compreende o Município de Realeza, bem como a importância das doenças reprodutivas na eficiência reprodutiva dos rebanhos leiteiros, pretende-se com esse estudo, revisar a literatura sobre a Campilobacteriose e Tricomonose, disponibilizando informações capazes de contribuir para a adoção de medidas de controle e profilaxia destas doenças.

\section{Desenvolvimento}

A Tricomonose bovina é uma doença sexualmente transmissível (DST), infecciosa e tendo como agente o protozoário Tritrichomonas foetus (GOMES, 2015). É um protozoário ativamente móvel e anaeróbio, se multiplica por divisão binária, é sensível ao calor e aos desinfetantes comuns, e sobrevive por poucos dias no ambiente (SPOSITO FILHA; OLIVEIRA, 2009).

Apresenta distribuição mundial e pode ocorrer em qualquer região onde existam bovinos, tanto de corte quanto de leite (SPOSITO FILHA; OLIVEIRA, 2009). No Brasil, a enfermidade foi diagnosticada pela primeira vez em touros doadores de sêmen em uma central de inseminação no Rio Grande do Sul (RIET-CORREA et al., 2007).

Em fêmeas, o primeiro sinal clínico é a foliculite e vestibulite, devido à maior deposição de tricomonas na porção ventral da vagina e do vestíbulo (GOMES, 2015). Além disso, são relatados endometrite, piometra, cervicite, vaginite, irregularidades do estro, abortamento precoce, esterilidade temporária e morte do feto (SPOSITO FILHA; OLIVEIRA, 2009). Frequentemente o abortamento ocorre entre o terceiro e o quinto mês de gestação (RIET-CORREA et al., 2007). Os machos são assintomáticos, podendo atuar como fonte de infecção durante toda vida reprodutiva (PAZ JÚNIOR et al., 2010). Em machos, o parasita pode ser observado com maior frequência na cavidade prepucial, mucosa peniana e na porção inicial da uretra. Em fêmeas, o protozoário inicialmente se multiplica na vagina. Após alguns dias todo o trato genital pode estar contaminado (SPOSITO FILHA; OLIVEIRA, 2009). Se ocorrer gestação, usualmente ocorre a morte do embrião e alteração do ciclo estral. Se a gestação continuar, pode ocorrer aborto antes do quarto mês com persistência do corpo lúteo, destruição e maceração do feto, além de piometra (RIET-CORREA et al., 2007).

A transmissão se dá por via sexual e as fêmeas se infectam após a cópula com touro infectado ou vice-versa, quando ocorre infecção em quase $100 \%$ dos casos (ALVES et al., 2011). Além do contato sexual, há evidências de que esse parasita possa ser veiculado de modo indireto, por meio de corrimento vaginal transferido para cama de feno, vagina artificial contaminada e instrumento obstétrico (SPOSITO FILHA; OLIVEIRA, 2009), ou através da inseminação ar- 
tificial com equipamentos ou sêmen contaminados (RIET-CORREA et al., 2007).

O diagnóstico de Tricomonose baseia-se no histórico reprodutivo do rebanho, além do isolamento e identificação do T. foetus. Para o isolamento do protozoário utilizam-se, principalmente, amostras colhidas de muco vaginal, lavado prepucial, sêmen e conteúdo estomacal de feto abortado (SPOSITO FILHA; OLIVEIRA, 2009). Em fêmeas a infecção é temporária, sendo eliminada apóstrês a seis ciclos estrais (ALVES et al., 2011).

O controle da infecção causada pelo $T$. foetus baseia-se na eliminação do protozoário da propriedade, especialmente na transmissão do agente dos machos para as fêmeas (GOMES, 2015). Os machos utilizados na reprodução devem ser periodicamente testados para a presença de $T$. foetus e somente deve-se introduzir no rebanho, touro que seja comprovadamente negativo, após pelo menos três exames consecutivos (SPOSITO FILHA; OLIVEIRA, 2009).

Como medidas de controle recomendam-se uso da inseminação artificial com sêmen e equipamentos adequados e utilização de machos jovens (dois a três anos), provenientes de propriedades livres da infecção e testados duas a três vezes (RIET-CORREA, et al, 2007). Em rebanhos nos quais a inseminação artificial é praticada em todas as fêmeas em reprodução, a Tricomonose não se mantém (NASCIMENTO; SANTOS, 2011).

A Campilobacteriose genital bovina é uma enfermidade de caráter eminentemente venéreo, causada pelo $C$. fetus subp. venerealis (PELLEGRIN, 2001), que é um bastonete gram-negativo, espiralado, em forma de vírgula ou em "S", possui um ou dois flagelos polares e não forma esporos (ALVES et al., 2011). Possui capacidade de aderência bacteriana que foi confirmada por meio da microscopia óptica, além da determinação de percentagem de bactérias aderidas que foi realizada em lâminas tingidas imunoquimicamente (CHIAPPARRONE et al., 2011).

$\mathrm{Na}$ vaca o patógeno coloniza a mucosa da vagina, cérvix e ovidutos (PELLEGRIN, 2001), atingindo as células epiteliais do útero (CHIAPPARRONE et al., 2011). No touro esse agente coloniza apenas a mucosa prepucial, e isto se dá devido as variações que a bactéria sofre no decorrer da doença, assim não aparenta caráter invasivo e não induz produção de anticorpos (ZIECH et al., 2014). Cerca de um terço das vacas infectadas torna-se portadora (QUINN et al., 2005). Touros velhos, com mais de cinco anos, uma vez infectados podem se tornar portadores por toda vida, enquanto touros jovens adquirem a infecção por pouco tempo, recuperando-se espontaneamente (RIET-CORREA et al., 2007).

O touro não apresenta sinais clínicos que façam suspeitar da enfermidade, mantendo a libido e a capacidade fertilizante do sêmen, cujas características físicas e químicas não se alteram (RIET-CORREA et al., 2007). Em fêmeas, essa doença é caracterizada por infertilidade temporária associada à morte embrionária precoce, com retorno ao estro em períodos irregulares (QUINN et al., 2005), além do aumento do intervalo de estro a gestação, maior intervalo de partos e raramente abortos, ocorrendo em três a cinco por cento das fêmeas doentes, entre o quinto e sétimo mês de gestação. Após três ou quatro meses ocorre recuperação do endométrio e o animal começa a ciclar novamente (RIET-CORREA et al., 2007).
O C. fetus subsp. venerealis é transmitido por touros portadores assintomáticos durante o coito a vacas susceptíveis (QUINN et al., 2005). A transmissão dos touros infectados para fêmeas alcança quase $100 \%$ e a infertilidade, representada pela repetição de estro, atinge mais comumente as novilhas, sendo que o aborto, em torno do quinto mês de gestação ocorre em menos de $10 \%$ das acometidas (PELLEGRIN, 2001). O período infértil que se segue à invasão uterina pode prolongar-se por três a cinco meses, após o desenvolvimento da imunidade natural (QUINN et al., 2005).

Oliveira et al. (2015) realizaram um estudo e determinaram a prevalência da doença no estado de Pernambuco, sendo $10,4 \%$ (27/258). A prevalência encontrada é semelhante a prevalencia em outras regiões do país.

A observação das manifestações clínicas, do histórico dos animais e da avaliação dos dados zootécnicos da propriedade podem auxiliar no diagnóstico da Campilobacteriose (ALVES et al., 2011), que pode ser diagnosticada por testes muco cervicovaginal, quanto a presença de anticorpos contra antígenos do agente (HIRSH; ZEE, 2009). Amostras para a cultura ou observação são mais bem obtidas no prepúcio do touro, onde o esmegma é coletado por aspiração com a ponta de uma pipeta de inseminação (HIRSH; ZEE, 2009). Estudos epidemiológicos realizados nas últimas décadas indicaram que a prevalência de aborto bovino devido a Campilobacteriose é alta no rebanho brasileiro (NASCIMENTO; SANTOS, 2011).

A melhor forma de controle de C. fetus subsp. venerealis é a prevenção. Práticas saudáveis e cuidadosas e manejo reduzem as chances de introdução do agente no rebanho (HIRSH; ZEE, 2009). Há alguns fatores de riscos que estão interligados com a campilobacteriose bovina, utilização de manejo reprodutivo com monta natural, bem como o uso de touros com idade superior a quatro ou cinco anos no rebanho (PELLEGRIN, 2001).

\section{Considerações Finais}

Diante do cenário atual da produção de leite, o pequeno produtor busca cada vez mais diminuição dos custos de produção, melhoria na qualidade do leite e na genética dos animais. No entanto, a sanidade reprodutiva do rebanho fica a desejar, principalmente pela falta de informação e diagnóstico das doenças reprodutivas. Dessa forma, o desenvolvimento de estudos como esse, possibilita informações capazes de contribuir para a adoção de medidas de controle e profilaxia destas doenças.

\section{Referências}

ALVEZ, T. M. et al. Compilobacteriose genital bovina e tricomonose genital bovina: epidemiologia diagnóstico e controle. Pesquisa Veterinária Brasileira, v. 31, n. 4, p. 336-344, 2011.

\section{BOTELHO, M. P. A. Deteç̧ão de Tritrichomonas foetus e Campylobacter fetus ssp. veneralis em touros por meio da PCR e PCR multiplex. Lavras: UFLA, 2014.}

CHIAPPARRONE, M. L. et al. Quantitative anlysis of Campylobacter fetus veneralis adhesion to bovine 
reproductive tract cell cultures. Brazilian Journal of Veterinary Research and Animal Science, v. 48, n. 1, p. 73-78, 2011.

DEPARTAMENTO DE ECONOMIA RURAL DA SECRETARIA DE ESTADO DA AGRICULTURA E DO ABASTECIMENTO - DERAL/SEAB. Leite. Cultura Análise da Conjuntura Agropecuária, 2012/13.

GOMES, M. J. P. Tritrichomonas foetus: tricomonose/ tricomoníase bovina. FAVET-UFRGS, 2015.

HIRSH, D. C.; ZEE, Y. C. Microbiologia Veterinária. Rio de Janeiro: Guanabara Koogan, 2009, 446p.

LEAL, D. R. et al. Prevalência da campilobacteriose e da tricomonose genitais bovinas no Distrito Federal e em seu entorno. Revista Brasileira Reprodução Animal. v. 36, n. 4, p. 256-259, 2012.

LEITE, T. E. et al. Eficiência produtiva e reprodutiva em vacas leiteiras. Ciência Rural, v. 31, n. 3, p. 467-472, 2001.

NASCIMENTO, E. F.; SANTOS, R. L. Patologia da reprodução dos animais domésticos. 3 ed. Rio de Janeiro: Guanabara Koogan, 2011, 153p.

OLIVEIRA, J. M. B. Prevalence and risk factors associated with bovine genital campylobacteriosis and bovine trichomonosis in the state of Pernambuco, Brazil. Tropical Animal Health Production, n. 47. p. 549-555, 2015.

ORGANIZAÇÃO PAN-AMERICANA DE SAÚDE. MINISTÉRIO DA AGRICULTURA PECUÁRIA E ABATECIMENTO. Manual veterinário de colheita e envio de amostras. 1 ed. Brasília, 2010, 218p.

PAZ JÚNIOR, C. J. et al. Frequência de infecção por Tritrichomonas foetus (RIED MULLER, 1928) em bovinos leiteiros do município de Sanharó - PE .Medicina Veterinária, v. 4, n.1, p. 6-11, 2010.

PELLEGRIN, A. O. Campilobacteriose genital bovina na sub-região da Nhecolândia do Pantanal Sul-Matogrossense e proposição de novas técnicas de diaganóstico. Tese de Doutorado no Programa de Pós-Graduação em Ciencia animal pela Universidade Federal de Minas Gerais. Belo Horizonte, 2001.

QUINN, P. J. et al. Microbiologia veterinária e doenças infecciosas. Porto Alegre: Artmed, 2005, 512p.

RIET-CORREA, F. et al. Doenças de ruminantes e equídeos. v.1. 3 ed. São Paulo: Varela, 2007, 722p.

SPÓSITO FILHA, E.; OLIVEIRA, S. M. Tricomonose Bovina. Instituto Biológico, v. 71, n. 1, p. 9-11, 2009.

ZIECH, R. E. et al. 2014. Campylobacter fetus em bovinos no estado do Rio Grande do Sul. Ciência Rural, v. 44, n. 1, p. 141-146, 2014.
Recebido em: 26.11.2016

Aceito em: 14.02.2017 